\title{
A homing mechanism for bone marrow-derived progenitor cell recruitment to the neovasculature
}

\author{
Hui Jin, ${ }^{1}$ Aparna Aiyer, ${ }^{1}$ Jingmei Su, ${ }^{1}$ Per Borgstrom, ${ }^{2}$ Dwayne Stupack, ${ }^{1,3}$ \\ Martin Friedlander, ${ }^{4}$ and Judy Varner ${ }^{1,5}$
}

\begin{abstract}
${ }^{1}$ Moores UCSD Cancer Center, University of California, San Diego, La Jolla, California, USA. ${ }^{2}$ Sidney Kimmel Cancer Center, San Diego, California, USA. ${ }^{3}$ Department of Pathology, University of California, San Diego, La Jolla, California, USA. ${ }^{4}$ Department of Cell Biology, The Scripps Research Institute, La Jolla, California, USA. ${ }^{5}$ Department of Medicine, University of California, San Diego, La Jolla, California, USA.
\end{abstract}

\begin{abstract}
$\mathrm{CD}^{+} 4^{+}$bone marrow-derived progenitor cells contribute to tissue repair by differentiating into endothelial cells, vascular smooth muscle cells, hematopoietic cells, and possibly other cell types. However, the mechanisms by which circulating progenitor cells home to remodeling tissues remain unclear. Here we show that integrin $\alpha_{4} \beta_{1}$ (VLA-4) promotes the homing of circulating progenitor cells to the $\alpha_{4} \beta_{1}$ ligands VCAM and cellular fibronectin, which are expressed on actively remodeling neovasculature. Progenitor cells, which express integrin $\alpha_{4} \beta_{1}$, homed to sites of active tumor neovascularization but not to normal nonimmune tissues. Antagonists of integrin $\alpha_{4} \beta_{1}$, but not other integrins, blocked the adhesion of these cells to endothelia in vitro and in vivo as well as their homing to neovasculature and outgrowth into differentiated cell types. These studies describe an adhesion event that facilitates the homing of progenitor cells to the neovasculature.
\end{abstract}

\section{Introduction}

Bone marrow-derived, CD34+ progenitor cells have been shown to promote the repair of damaged tissues, offering promise for the treatment of hereditary and acquired human diseases (1-13). These cells differentiate into endothelia, hematopoietic cells, and possibly neurons, fibroblasts, and muscle (1-13). CD $34^{+}$and $\mathrm{AC} 133^{+}$progenitor cells may participate in neovascularization by differentiating into endothelial cells (1-6). Neovascularization stimulates healing of injured tissues $(1-7,14)$ but also promotes tumor growth and inflammatory disease (14-17). Circulating bone marrow-derived progenitor cells home to sites of neovascularization (1-7,14-17), where they can give rise to approximately $15 \%$ of the tumor neovasculature (16). These cells may thus participate in tissue regeneration or pathogenesis (8-13). Although some studies indicate progenitor cells differentiate into a variety of cell types (1-13), others suggest they may fuse with differentiated hepatocytes or muscle cells, creating the appearance of differentiation $(18,19)$. Nevertheless, the evidence that these cells promote tissue repair is strong, although the molecular mechanism(s) that promote the homing and recruitment of bone marrow-derived progenitor cells to remodeling tissues remain unclear.

Integrins and their ligands promote endothelial cell migration and survival during angiogenesis (20). However, our studies demonstrate that the fibronectin receptor $\alpha_{4} \beta_{1}$ plays 2 unique roles during angiogenesis. We recently found that this integrin mediates intercellular adhesion and survival of endothelial cells and pericytes during blood vessel formation in vivo and that this integrin is required for angiogenesis (21). However, integrin $\alpha_{4} \beta_{1}$ is best

Nonstandard abbreviations used: ACTB-EGFP, EGFP expressed under control of the chicken $\beta$-actin promoter; CMTMR, 5-and-6-4-chloromethylbenzoylamino-tetramethylrhodamine; CS-1, conecting segment-1; EGFP, enhanced GFP; Lin, lineage; LLC, Lewis lung carcinoma; rsVCAM, recombinant soluble VCAM.

Conflict of interest: The authors have declared that no conflict of interest exists. Citation for this article: J. Clin. Invest. doi:10.1172/JCI24751. known as a lymphocyte integrin that mediates adhesion of circulating lymphocytes to VCAM expressed on activated endothelia in inflamed tissues, thereby promoting extravasation of lymphocytes into inflamed tissue $(22,23)$. In the studies presented here, we found that integrin $\alpha_{4} \beta_{1}$ promotes the homing of circulating bone marrow-derived progenitor cells to the $\alpha_{4} \beta_{1}$ ligands, VCAM, and cellular fibronectin, which are expressed on neovasculature. By regulating the homing of these cells, this integrin also promotes their participation in angiogenesis and tumor growth.

\section{Results}

$\mathrm{CD} 34^{+}$cells home to the tumor periphery. Bone marrow-derived progenitor cells have been shown to contribute to tumor neovasculature and other tissue repair processes by differentiating into endothelial cells, hematopoietic cells, and other cell types (1-7). To understand how progenitor cells as well as other circulating cells home to remodeling tissues, such as the tumor microenvironment, we initially employed real time-intravital microscopy to study the movement of circulating human cells transplanted into mice with breast carcinomas (Figures 1 and 2). CD34+ progenitor cells were isolated by magnetic bead affinity selection from human PBMCs; the purified CD $34^{+}$comprised approximately $0.1 \%$ of the total PBMC population and was $98 \%$ pure (Figure $3 \mathrm{~A}$ ). CD34+-positive cells were labeled with a red fluorescent cell tracking dye, 5-and-64-chloromethylbenzoylamino-tetramethylrhodamine (CMTMR). One million fluorescent $\mathrm{CD} 34^{+}$cells per mouse were injected into the tail veins of nude mice implanted with murine N202 breast carcinoma spheroids on mammary fat-pads under dorsal skinfold chambers (Figure 1A). Intravital microscopy enabled us to track cell homing within tumors and adjacent normal tissue. Tumors (Figure 1B) and associated blood vessels (Figure 1C) were visible in the transparent chambers, permitting analysis of real-time cell movement within the vasculature. Within a few minutes after intravascular injection, human bone marrow-derived CD $34^{+}$cells were observed circulating within the tumor vasculature. Approxi- 


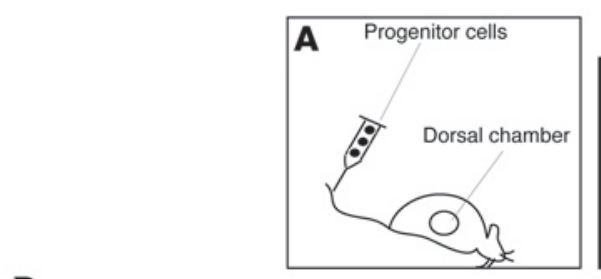

D
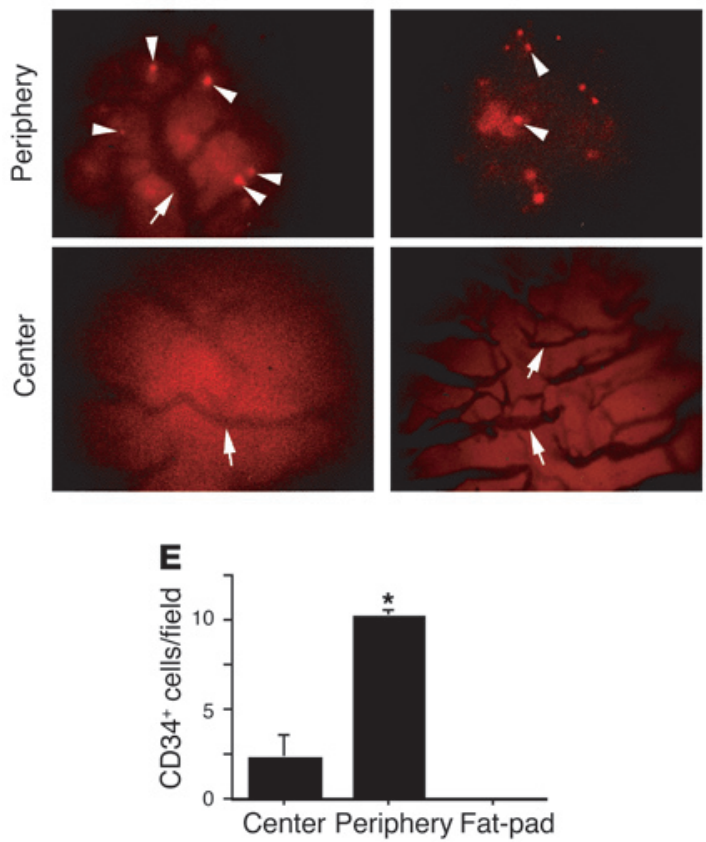

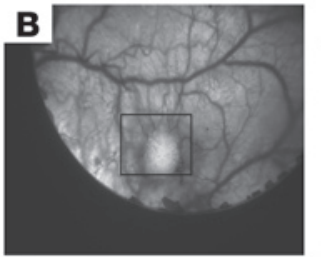

$\mathbf{F}$
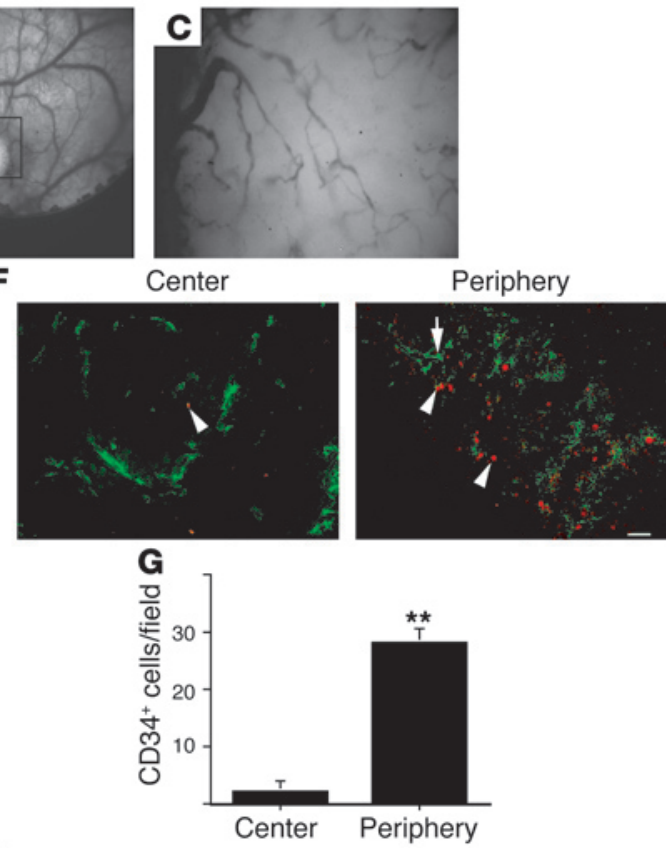

H

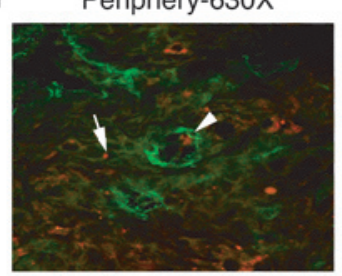

Periphery-630X

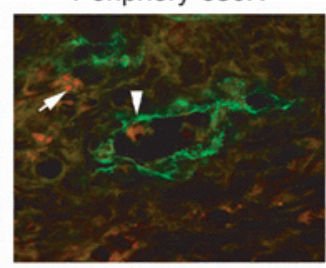

\section{Figure 1}

Human $\mathrm{CD}_{34}{ }^{+}$progenitor cells home to peripheral tumor vasculature. (A) Nude mice with GFP-N202 breast carcinomas under dorsal skinfold transparent chambers are injected with labeled progenitor cells. (B) Real-time video microscopy: GFP tumors in transparent chambers. Magnification, $\times 10$. (C) Tumor vasculature is visible in the transparent chambers. Magnification, $\times 100$. (D) Two images each of peripheral and central tumor vascular beds at 15 minutes after injection in animals injected with CMTMR-labeled CD34+ cells (arrowheads). Magnification, $\times 200$. Blood vessels are observed as dark channels (arrows). (E) Average number of CMTMR CD34+ cells in the tumor center, tumor periphery, and fat-pad per $\times 200$ field \pm SEM. ${ }^{*} P<0.0019$. (F) Five micron cryosections of the same tumors from animals injected with CD34+ cells were fixed in acetone, then incubated with rat anti-mouse CD31 and goat anti-rat FITC antibodies and photographed. Magnification, $\times 200$. Arrowheads indicate CD34+ cells. Arrows indicate CD31+ blood vessels. Scale bar: $50 \mu \mathrm{m}$. (G) Average number of CD34+ cells per $\times 200$ microscopic field in $5 \mu \mathrm{m}$ cryosections. ${ }^{*} P<0.015$. (H) Cryosections from F observed at $\times 630$ magnification indicate CD34+ cells (arrows) are found adhering to the blood vessel wall or within tissues near blood vessels (arrowheads).

mately 10 minutes after injection, fluorescent cells were observed first rolling, then arresting in blood vessels at the tumor periphery (Figure 1D), but not at the tumor center (Figure 1D), neighboring breast fat-pad, or uninvolved skin (not shown). Cell homing was not dependent on the density of blood vessels in the tumor tissue, as extensive vascularization was observed in the center and periphery of the tumor (Figure 1D). Within 15 minutes after injection, no further fluorescent cells were observed arresting in blood vessels. The arrested cells remained in the tumor periphery during the 30-minute initial observation period. From 5- to 10-fold more cells arrested in the tumor periphery than in the tumor center or in the neighboring fat-pad (Figure 1E).

Postmortem analysis of thin sections of tumors isolated $60 \mathrm{~min}-$ utes after cell injection confirmed that $\mathrm{CD} 34^{+}$cells had selectively arrested in the tumor periphery rather than tumor center (Figure 1, F and G; Supplemental Figure 1; supplemental material available online with this article; doi:10.1172/JCI24751DS1). Important- ly, CD34+ cells were observed adhering to vessel walls within the lumens of $\mathrm{CD} 31^{+}$blood vessels, within vessel walls, and near the vessels within the tumor parenchyma (Figure $1 \mathrm{H}$ ). These studies indicate that bone marrow-derived progenitor cells home selectively to the growing peripheral tumor vasculature and transmigrate into tumor tissue, suggesting that specific cell attachment and migration mechanisms may play a role in this homing response.

To determine whether CD34- circulating cells (such as monocytes) also arrest within the peripheral vasculature of tumors, CD34- mononuclear cells isolated from peripheral blood were labeled with a red fluorescent cell tracking dye and were injected into circulation of mice implanted with $\mathrm{GFP}^{+} \mathrm{N} 202$ breast carcinoma spheroids. Fluorescent cells were observed first rolling, then arresting in blood vessels at the tumor periphery (Figure 2A) but not at the tumor center (Figure 2A), neighboring breast fatpad (Figure 2A), or uninvolved skin (not shown). Within 15-20 minutes after injection, no further fluorescent cells were observed 


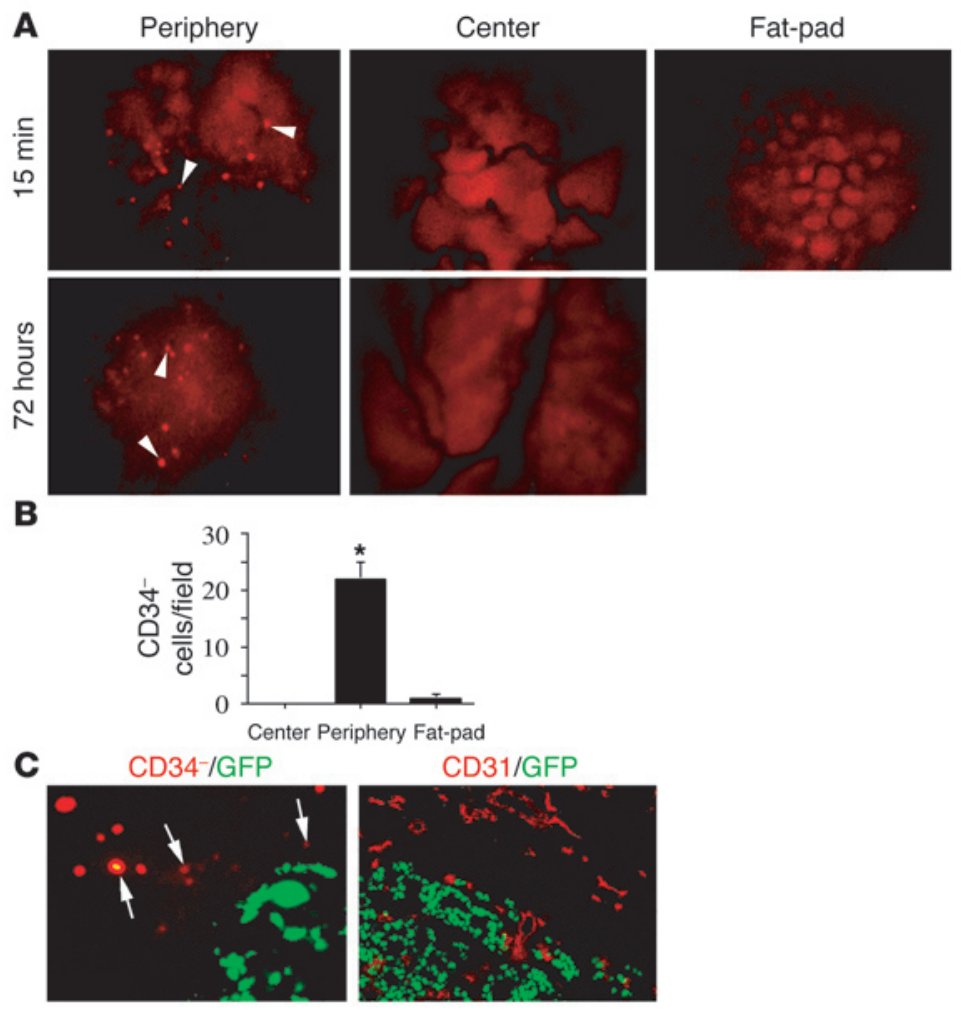

Figure 2

Human CD34- mononuclear cells also home to peripheral tumor vasculature. (A) Intravital microscopy of CMTMR-labeled CD34- mononuclear cells homing to tumor vessels. Shown are peripheral and central tumor vascular beds as well as neighboring fat-pad at 20 minutes after injection in animals injected with CMTMR-labeled CD34- mononuclear cells (arrowheads). Magnification, $\times 200$. Tumor center and periphery at 72 hours after injection of cells are also shown. (B) Average number of CMTMR CD34- cells in the tumor center, tumor periphery, and fat-pad per $\times 200$ field \pm SEM after 15 minutes. ${ }^{*} P<0.0009$. (C) Postmortem tumor section shows CD34- cells (red; arrows) at the $\mathrm{GFP}^{+}$(green) tumor periphery (left). Magnification, $\times 400$. Also shown are CD31+ blood vessels (red) at the GFP+ (green) tumor periphery (right). Magnification, $\times 200$.

arresting in blood vessels. The arrested cells remained in the tumor periphery during the 30-minute initial observation period and for up to 3 days later (Figure 2A). A significantly greater number of cells arrested in the tumor periphery than elsewhere (Figure 2B). Postmortem analysis of tissues confirmed that the human CD34cells were present only at the $\mathrm{GFP}^{+}$tumor periphery, just beyond the edge of the $\mathrm{GFP}^{+}$tumor (Figure $2 \mathrm{C}$ ), even though CD31+ blood vessels were present both within the tumor and at the periphery of the tumor (Figure 2C). These studies show that CD34- cells have the capacity to home to the tumor peripheral vasculature as well.

Integrin $\alpha_{4} \beta_{1}$ is expressed by $C D 34^{+}$progenitor cells. To determine how circulating progenitor cells and other cells arrest in the peripheral tumor vasculature, we examined the roles of cell adhesion molecules in this process. Circulating cells such as lymphocytes utilize selectins to initiate contact with the blood vessel (rolling) and integrins $\alpha_{4}$ or $\beta_{2}$ to arrest on the endothelium and extravasate from the circulation $(22,23)$. Hematopoietic precursor cells also use integrin $\alpha_{4}$ to adhere to bone marrow endothelia and to home back to the bone marrow from the circulation (24-26). To evaluate a role for specific adhesion proteins in progenitor cell homing, we examined the expression of integrins on circulating CD $34^{+}$cells. CD $34^{+}$cells were isolated to $98 \%$ purity from human PBMCs by 3 rounds of anti-CD34 magnetic bead affinity chromatography. CD34 ${ }^{+}$cells expressed significant levels of integrins $\alpha_{4}(100 \%), \alpha_{5} \beta_{1}(99 \%), \alpha_{v} \beta_{3}(99 \%)$, and $\beta_{2}(68 \%)$ but little integrin $\alpha_{v} \beta_{5}$ (Figure $\left.3 \mathrm{~A}\right)$. The integrin $\alpha_{4}$ subunit can combine with either the $\beta_{1}$ or the $\beta_{7}$ subunits, although the $\beta_{7}$ subunit has been detected only in small subsets of bone marrow-derived cells. We observed that the $\mathrm{CD} 34^{+}$cell population expresses high levels of the integrin $\beta_{1}$ subunit but did not express the integrin $\beta_{7}$ subunit (Supplemental Figure 2 ). Thus, the integrin $\alpha_{4} \beta_{1}$ (VLA-4) is the primary $\alpha_{4}$ integrin on CD34 $4^{+}$ progenitor cells. Like CD34+ cells, CD34- mononuclear cells also express high levels of the same integrins (Supplemental Figure 3 ). While endothelial cells express high levels of integrins $\alpha_{5} \beta_{1}, \alpha_{v} \beta_{3}$, and $\alpha_{v} \beta_{5}$, they express low levels of integrin $\alpha_{4} \beta_{1}$, no $\beta_{2}$ integrins, and no CD133. Thus, as CD $34^{+}$cells express CD133 and high levels of $\alpha_{4} \beta_{1}$ and $\beta_{2}$ integrin, but no $\alpha_{v} \beta_{5}$, these cells are clearly not of endothelial origin (Figure $3 \mathrm{~A}$ ).

Integrin $\alpha_{4} \beta_{1}$ mediates progenitor cell adhesion to endothelia in vitro. We next determined whether integrins on $\mathrm{CD} 34^{+}$cells mediate adhesion to the vascular endothelia by plating fluorescently labeled cells on confluent EC monolayers in vitro. Human CD34+ cells bound strongly to ECs (Figure 3, $\mathrm{B}$ and $\mathrm{C})$. The adhesion of $\mathrm{CD} 34^{+}$cells to endothelia was blocked by antibodies to integrin $\alpha_{4}$ (Figure 3, B and C) and $\beta_{1}$ (Supplemental Figure 2 ) as well as by recombinant soluble VCAM (rsVCAM), another competitive inhibitor of integrin $\alpha_{4}$ function, but not by antibodies to other integrins (Figure 3, B and C). Together, these studies demonstrate that integrin $\alpha_{4} \beta_{1}$ selectively mediates the attachment of $\mathrm{CD}_{3} 4^{+}$progenitor cells to endothelia in vitro. As integrin $\alpha_{4} \beta_{1}$ is a receptor for connecting segment- 1 (CS-1) fibronectin, an alternatively spliced form of cellular fibronectin (27), and for VCAM, an immunoglobulin superfamily molecule expressed on endothelia in inflamed tissues (22), these studies indicate that $\alpha_{4}$-VCAM or $\alpha_{4}$-fibronectin interactions can promote progenitor cell adhesion to endothelia. Indeed, proliferating endothelial cells express the $\alpha_{4} \beta_{1}$ ligands cellular fibronectin (27) and VCAM (Figure 3D). $\mathrm{CD} 34^{+}$cells also adhere to the CS- 1 domain of cellular fibronectin in an integrin $\alpha_{4} \beta_{1}$-dependent manner (Figure $3 \mathrm{E}$ ). By comparison, CD34- mononuclear cells also express high levels of integrin $\alpha_{4} \beta_{1}$ and adhere to endothelia and CS-1 fibronectin in an $\alpha_{4} \beta_{1-}$ dependent manner (Supplemental Figure 3).

Integrin $\alpha_{4} \beta_{1}$ mediates progenitor cell adhesion to endothelia in vivo. To determine if integrin $\alpha_{4} \beta_{1}$ mediates CD34+ progenitor cell or CD34mononuclear cell attachment to endothelia in vivo, fluorescently labeled cells were injected into nude mice bearing N202 tumors in the presence of integrin antagonists. Postmortem analysis of these tumors isolated within 60 minutes of cell injection confirmed that an anti- $\alpha_{4} \beta_{1}$ antibody inhibited CD34 ${ }^{+}$cell arrest within tumors (Figure 4, A and B). Similarly, fluorescently labeled CD34+ cells were injected into nude mice with Lewis lung carcinoma (LLC) tumors. Postmortem analysis of these tumors isolated within 60 minutes of $\mathrm{CD}_{3} 4^{+}$cell injection showed that progenitor cells had arrested in the periphery of LLC tumors (Figure 4C). Few human cells were observed in tumor centers (data not shown). Anti- $\alpha_{4} \beta_{1}$ 

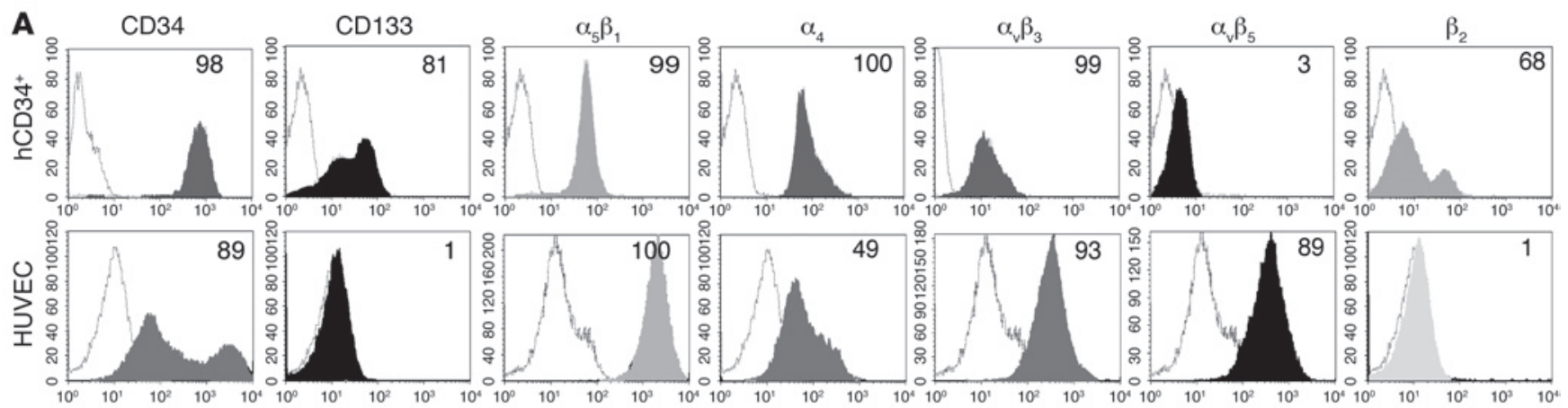

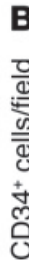

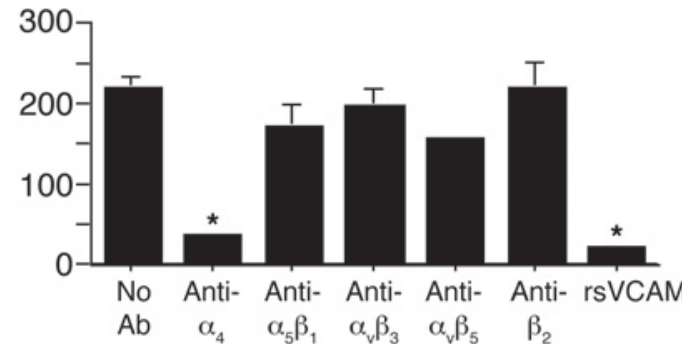

C

D
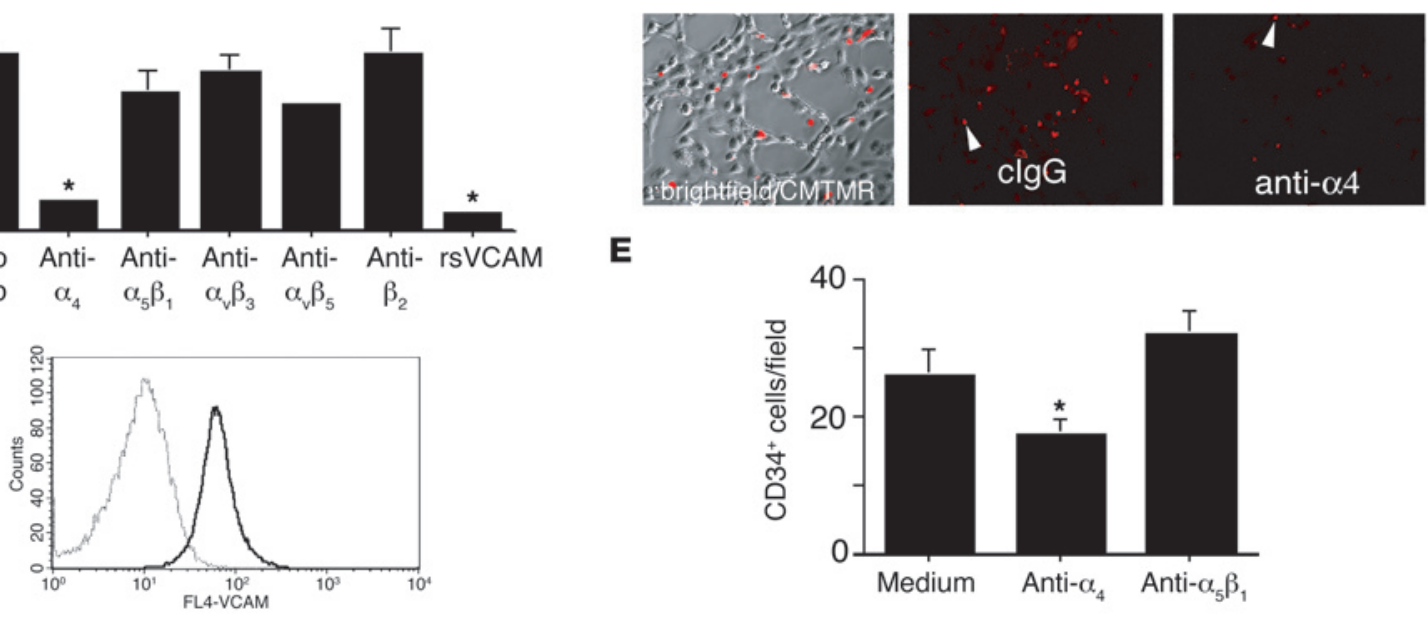

E

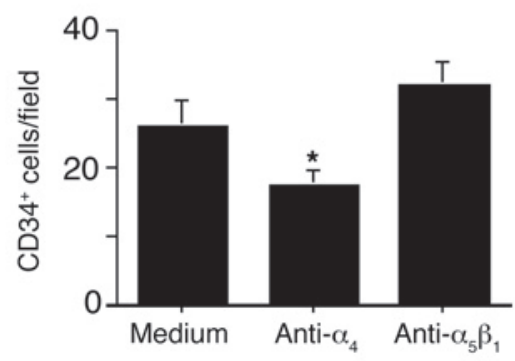

Figure 3

Integrin $\alpha_{4} \beta_{1}$ mediates adhesion of human CD34+ cells to endothelia. (A) FACs profiles for CD34, CD133, and $\alpha_{4} \beta_{1}, \alpha_{5} \beta_{1}, \alpha_{v} \beta_{3}, \alpha_{v} \beta_{5}$, and $\beta_{2}$ integrins on $\mathrm{CD}_{34}{ }^{+}$cells and HUVECs. FACS profile in outline represents fluorescence of isotype control antibody. Percentage of positive cells is indicated by number in right-hand corner of each profile. hCD34+, human $\mathrm{CD}_{4} 4^{+}$. (B and $\left.\mathbf{C}\right) \mathrm{CD} 34^{+}$cell adhesion to EC monolayers in the presence of medium, anti- $\alpha_{4} \beta_{1}, \alpha_{5} \beta_{1}, \alpha_{v} \beta_{3}, \alpha_{v} \beta_{5}$, or $\beta_{2}$, or rsVCAM. (B) Average number of CD34+ cells adhering to EC per $\times 200$ microscopic field \pm SEM. ${ }^{*} P<0.002$ (anti- $\left.\alpha_{4} \beta_{1}\right)$ and $P<0.005$ (rsVCAM). (C) Red fluorescent CD34+ cells adhering to ECs as in B. clgG indicates control, isotype-matched immunoglobulin. (D) FACs profile of VCAM expression on cultured HUVECs. (E) Average number of cells adhering to recombinant CS-1 fibronectin fragments in the presence of culture medium or medium with antibody antagonists of integrin $\alpha_{4} \beta_{1}$ (HP2/1) or integrin $\alpha_{5} \beta_{1}$ (JBS5) per $\times 200$ microscopic field \pm SEM.

antibodies, but not antagonists of other integrins, including integrins $\alpha_{v} \beta_{3}$ (Figure 4, C and D) and $\alpha_{v} \beta_{5}$ (not shown), substantially reduced progenitor cell accumulation in tumors. Antibody antagonists of human $\alpha_{4} \beta_{1}$ also inhibited the homing of CD34- cells to N202 tumor vessels. Intravital microscopy imaging over 30 minutes demonstrated that no CD34- cells arrested in tumor vessels in the presence of anti-integrin $\alpha_{4} \beta_{1}$ antibodies (Figure 4, E and F). While CD $34^{+}$progenitor cells and CD34- cells homed significantly to tumors, neither cell type homed significantly to adjacent normal tissues, to the lung (Supplemental Figure 4), or to the bone marrow (not shown). In contrast, i.v.-injected Chinese hamster ovary tumor cells expressing integrin $\alpha_{4} \beta_{1}$ were entrapped solely in the lung and not in tumors, suggesting that circulating bone marrow-derived cells specifically home to the tumor vasculature. These studies indicate that integrin $\alpha_{4} \beta_{1}$ regulates the homing of human bone marrow-derived progenitor cells and other mononuclear cells to the neovasculature in vivo. These results discount nonspecific leakage of cells from tumor vessels as a means to explain these findings because progenitor cells do not lodge in central tumor vessels, and integrin $\alpha_{4} \beta_{1}$-expressing tumor cells do not lodge in tumors.
Human $\mathrm{CD} 4^{+}$progenitor cells have been previously shown to differentiate into endothelial cells in vivo and to thereby participate in blood vessel formation in vivo (1-3). We also found that a subset of $\mathrm{CD} 34^{+}$progenitor cells injected into animals bearing subcutaneous tumors differentiated into endothelial cells that helped to form blood vessel structures (Supplemental Figure 5). Importantly, antagonists of human integrin $\alpha_{4} \beta_{1}$ but not antagonists of integrin $\alpha_{v} \beta_{3}$ inhibited CD34+ $4^{+}$progenitor cell differentiation into endothelial cells (Supplemental Figure 5). These human $\mathrm{CD} 4^{+}$cells in CD31+ blood vessels expressed the proliferating cell antigen Ki67, indicating their proliferative status (Supplemental Figure 5). These studies suggest that integrin $\alpha_{4} \beta_{1}$ regulates CD $34^{+}$ progenitor cell roles in blood vessel formation by promoting progenitor cell homing to tissues.

Integrin $\alpha_{4} \beta_{1}$ promotes progenitor cell homing and subsequent blood vessel formation. To determine whether $\alpha_{4} \beta_{1}$ promotes murine progenitor cell homing and subsequent participation in neovascularization in vivo, we isolated murine bone marrow-derived progenitor cells from enhanced GFP (ACTB-EGFP [EGFP expressed under control of the chicken $\beta$-actin promoter]) mice. These cells have been previ- 
A

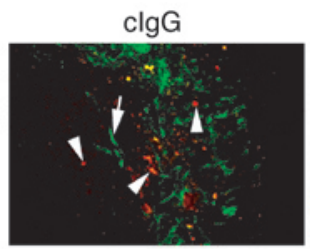

C
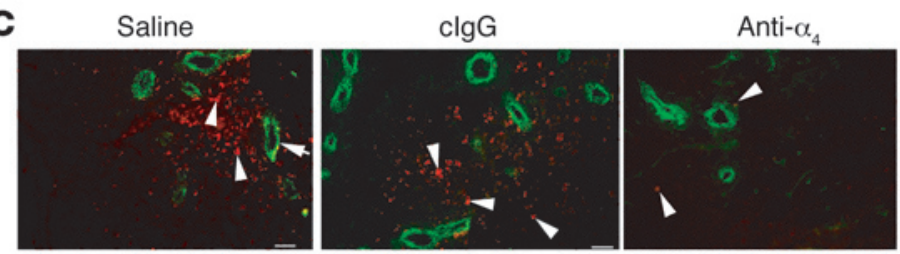

$\mathbf{E}$
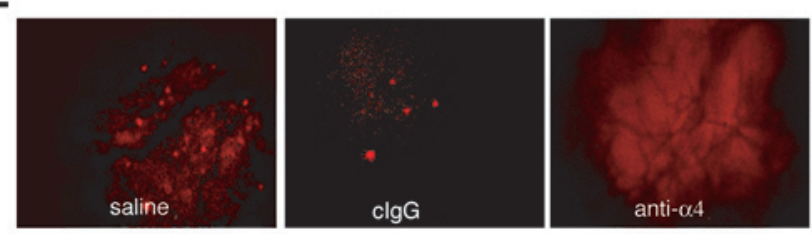

Figure 4

Integrin $\alpha_{4} \beta_{1}$ regulates CD34+ and CD34- cell homing to tumor vasculature. (A) Cryosections of N202 breast carcinomas from mice injected with CD34+ cells (red, arrowheads) and with either saline or anti-human $\alpha_{4} \beta_{1}$ antibodies. Blood vessels were identified by CD31 staining (green, arrows) and CD34+ cells by CMTMR labeling (red). (B) Average number of CD34+ cells \pm SEM per $\times 200$ field. ${ }^{*} P<0.0007$. (C) Cryosections of LLC lung carcinomas from mice injected with CD34+ cells (red, arrowheads) and with saline, anti-human $\alpha_{4} \beta_{1}$ antibodies, or isotype-matched control anti-integrin antibody (clgG, anti- $\alpha_{v} \beta_{3}$ ). Blood vessels were identified by CD31 staining (green, arrows). (D) Average number of CD34+ cells \pm SEM per $\times 200$ field. ${ }^{* *} P<0.0006$. (E) Video microscopy of tumors in animals injected with CMTMR-labeled CD34- human cells in the presence of saline, anti- $\alpha_{4} \beta_{1}$, or isotype-matched control anti-integrin antibody $\left(\right.$ anti- $\left.\alpha_{v} \beta_{3}\right)$. (F) Average number of CD34- cells \pm SEM per $\times 200$ field. ${ }^{\dagger} P<0.011$. Scale bars: $50 \mu \mathrm{m}$.

ously shown to participate in blood vessel formation in vivo by differentiating into endothelial cells $(3,28)$. We compared the integrin expression and adhesion profiles of mouse bone marrow-derived lineage-positive $\left(\mathrm{Lin}^{+}\right)$and lineage-negative $\left(\mathrm{Lin}^{-}\right)$progenitor cell populations and $\mathrm{Lin}^{-} \mathrm{Sca} 1^{+}$stem cell-enriched populations (29). Like human bone marrow-derived cells, murine $\mathrm{Lin}^{+}, \mathrm{Lin}^{-}$, and Lin-Sca $1^{+}$cells expressed high levels of integrins $\alpha_{4} \beta_{1}, \alpha_{5} \beta_{1}, \alpha_{v}$, and $\beta_{2}$ (Figure 5A). Each of these cell populations adhered to cultured ECs exclusively in an $\alpha_{4} \beta_{1}$-dependent manner, as only anti-integrin $\alpha_{4} \beta_{1}$ antibodies and rsVCAM, but not other integrin inhibitors, were able to suppress cell adhesion to endothelia (Figure 5, B-E).

To evaluate the ability of murine progenitor cells to home to tumor blood vessels, we injected $\mathrm{EGFP}^{+} \mathrm{Lin}^{-}$progenitor cells into animals with LLC tumors in the presence of saline, anti- $\alpha_{4} \beta_{1}$, antiVCAM, rsVCAM, or control IgG for 12 hours. We found that Lincells homed to tumors and that this homing was inhibited by anti$\alpha_{4} \beta_{1}$, rsVCAM, and anti-VCAM (Figure 6, A and B). These results indicate that Lin $^{-}$progenitor cells home to tumor neovasculature in an integrin $\alpha_{4} \beta_{1}$ - and VCAM-dependent manner.

To evaluate the ability of murine progenitor cells to participate in blood vessel formation, we injected $\mathrm{EGFP}^{+} \mathrm{Lin}^{-}$progenitor cells and $\mathrm{EGFP}^{+} \mathrm{Lin}^{+}$cells into animals with LLC tumors. After 5 days in vivo, EGFP $^{+}$Lin $^{-}$cells had homed to tumors, and some cells had formed EGFP $^{+}$blood vessels, primarily at the tumor periphery (Figure 6C and Supplemental Figure 6). Importantly, EGFP+ $\mathrm{Lin}^{+}$bone marrow-derived cells similarly injected homed to tumors but did not

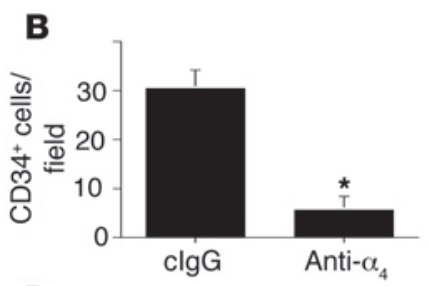

contribute to vessel formation although these cells homed to tumors and were found within the tumor tissue (Figure 6C). We next injected murine $\mathrm{EGFP}^{+} \mathrm{Lin}^{-}$progenitor cells into animals with LLC tumors in the presence or absence of anti- $\alpha_{4} \beta_{1}$ or isotype-matched anti-integrin $\beta_{2}$ antibodies. In contrast to control-treated animals, few $\mathrm{EGFP}^{+} \mathrm{Lin}^{-}$cells (Figure 6, D and E, and Supplemental Figure 6) or $\mathrm{EGFP}^{+}$blood vessels (Figure 6, D and F) were observed in tumors of anti$\alpha_{4} \beta_{1}$-treated mice.

We also injected murine $\mathrm{EGFP}^{+} \mathrm{Lin}^{+}$cells into animals with LLC tumors in the presence or absence of anti- $\alpha_{4} \beta_{1}$ or isotypematched anti-integrin antibodies. Numerous $\mathrm{EGFP}^{+} \mathrm{Lin}^{+}$cells were found in the tumor periphery of control-treated mice, but few $\mathrm{EGFP}^{+} \mathrm{Lin}^{+}$cells were observed in tumors of anti$\alpha_{4} \beta_{1}$-treated mice (Figure 6, $D$ and G). Our studies show that integrin $\alpha_{4} \beta_{1}$ promotes homing of circulating progenitor cells and other bone marrow-derived mononuclear cells to tumor vessels. These studies also indicate that inhibition of progenitor cell homing to the tumor vasculature prevents their participation in neovascularization by differentiation into endothelial cells. Our studies thus indicate that integrin $\alpha_{4} \beta_{1}$ mediates progenitor cell attachment to the tumor endothelium, extravasation, and subsequent participation in blood vessel formation.

Integrin $\alpha_{4} \beta_{1}$ ligands are expressed primarily at the tumor periphery. To determine whether ligands for the integrin $\alpha_{4} \beta_{1}$ are expressed by the tumor neovasculature, we examined tissues undergoing neovascularization for expression of the $\alpha_{4} \beta_{1}$ ligands VCAM and cellular fibronectin. Both VCAM and fibronectin are expressed in breast tumor endothelium, which is identified by anti-CD31 immunostaining (Figure 7). In fact, both ligands are expressed at much greater levels in the tumor periphery than in the tumor center (Figure 7). These ligands are rarely expressed by normal endothelia, although fibronectin was occasionally observed around large vessels in normal tissues (Figure 7). These results demonstrate that the $\alpha_{4} \beta_{1}$ ligands VCAM and fibronectin are expressed in the tumor periphery where they appear to promote the adhesion of $\alpha_{4} \beta_{1}{ }^{+}$progenitor cells.

Integrin $\alpha_{4} \beta_{1}$ but not $\beta_{2}$ integrins promote intrinsic bone marrowderived progenitor cell homing. Our studies indicate that integrin $\alpha_{4} \beta_{1}$ mediates the homing of bone marrow-derived progenitors to the peripheral neovasculature. To ascertain whether integrin 
A
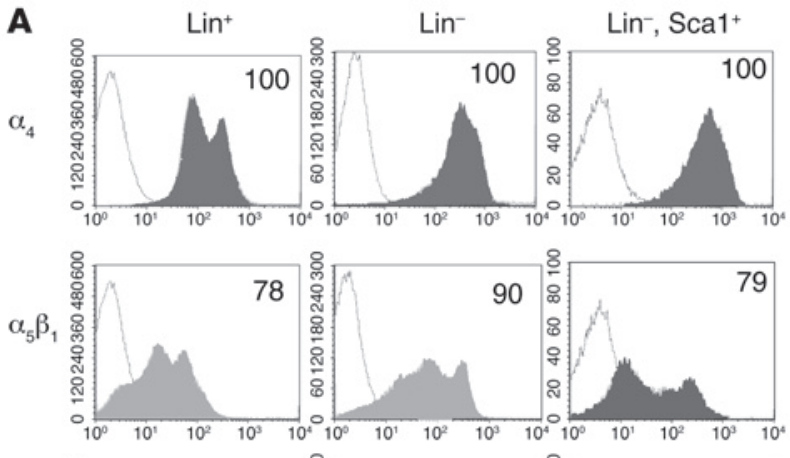

$\alpha_{\mathrm{v}}$
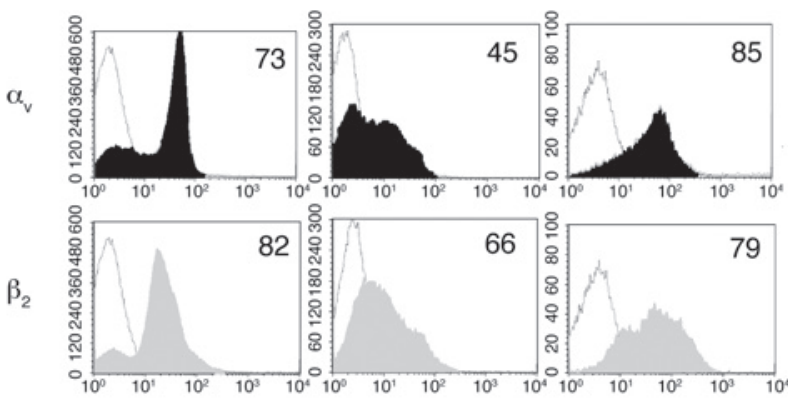

B No antibody
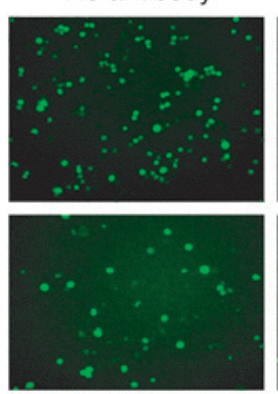

Anti- $\alpha_{v}$
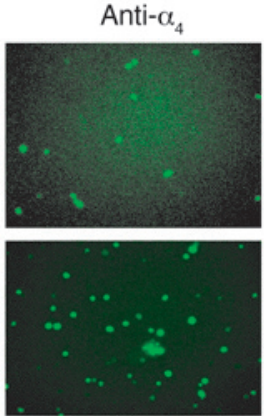

Anti- $\beta_{2}$
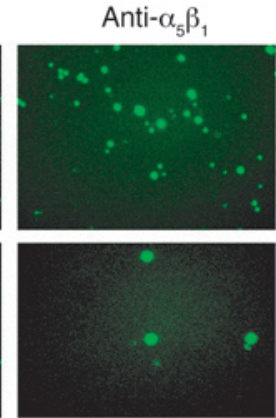

Anti-VCAM
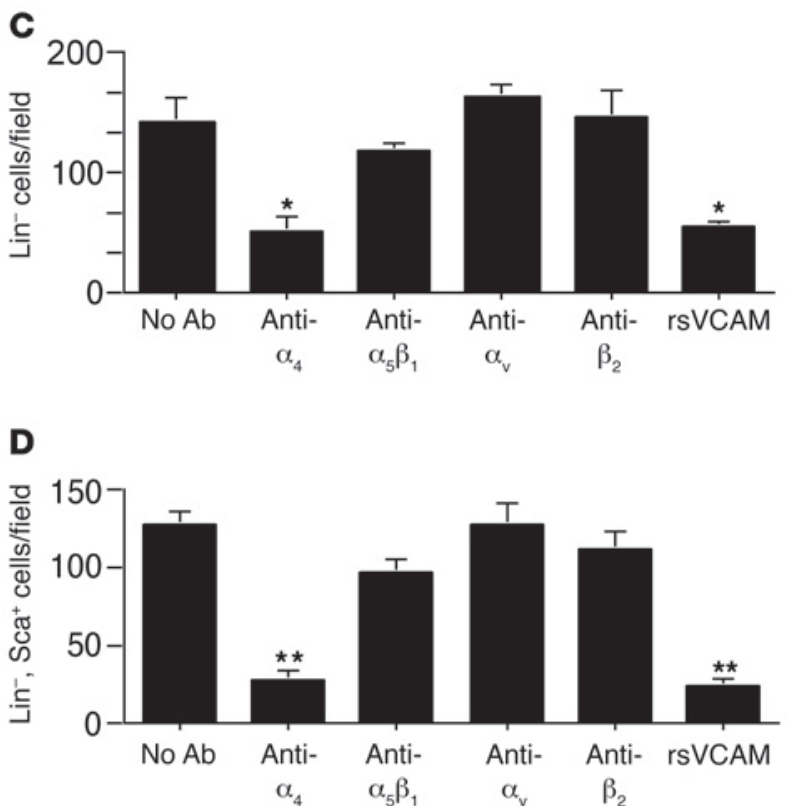

E

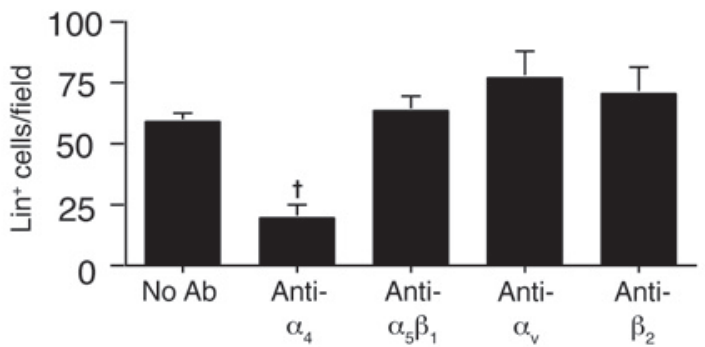

Figure 5

Integrin expression and function in murine bone marrow-derived progenitor cells. (A) FACs profiles for integrins $\alpha_{4} \beta_{1}, \alpha_{5} \beta_{1}, \alpha_{v}$, and $\beta_{2}$ on murine bone marrow-derived Lin', Lin- progenitor cells and Lin-Sca1+ ${ }^{+}$stem cells. The small numbers in the corners of each FACS profile indicate the percentage of positive cells. (B-E) Adhesion of murine bone marrow-derived Lin' and Lin- progenitor cells and Lin-Sca1 ${ }^{+}$stem cells to endothelial cell monolayers in the presence of medium, and function blocking antibodies against integrins $\alpha_{4} \beta_{1}, \alpha_{5} \beta_{1}, \alpha_{v}, \beta_{2}$, and rsVCAM. (B) Micrographs showing EGFP Lin- green fluorescent cells adhering to ECs in the presence of medium, anti- $\alpha_{4} \beta_{1}$, anti- $\alpha_{5} \beta_{1}$, anti- $\alpha_{v}$, or anti- $\beta_{2}$ (BD Biosciences - Pharmingen).

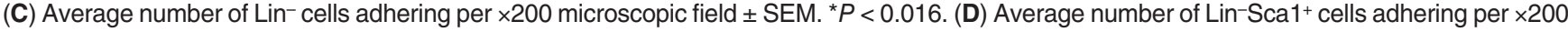
microscopic field \pm SEM. ${ }^{*} P<0.015$. (E) Average number of Lin ${ }^{+}$cells adhering per $\times 200$ microscopic field \pm SEM. ${ }^{\dagger} P<0.0065$.

$\alpha_{4} \beta_{1}$ plays a role in the natural homing of progenitor cells from bone marrow to neovasculature, mice were transplanted with bone marrow from Tie2LacZ mice. In Tie2LacZ mice, endothelial cells express $\beta$-galactosidase under the control of the promoter of the endothelial protein Tie2 (Supplemental Figures 7 and 8). Large vessels as well as small, single-celled vessels stain positively for $\beta$-galactosidase expression by both colorimetric (Supplemental Figure 7) and fluorescent immunostaining (Supplemental Figure 8) methods. In mice transplanted with Tie2LacZ bone marrow, bone marrow-derived endothelial cells expressed $\beta$-galactosidase under the control of the promoter of the endothelial protein Tie2 $(1,2)$.

Angiogenesis was stimulated in the Tie2LacZ bone marrowtransplanted mice by implantation of growth factor-reduced Matrigel saturated with VEGF or bFGF. These growth factors induced an angiogenic response as well as the homing of $\beta$-galactosidase-positive $\left(\beta \mathrm{Gal}^{+}\right)$cells (Figure 8, A and B). Many of these cells formed small vessels composed of single cells, which could be detected by microscopy at high magnification (Figure 8B). Treatment of mice with anti- $\alpha_{4} \beta_{1}$ but not anti-integrin $\beta_{2}$ function-blocking antibodies blocked the incorporation of $\beta \mathrm{Gal}^{+}$cells into the Matrigel (Figure 8, A-C). Immunological detection of $\beta$-galactosidase and CD31 expression demonstrated that many $\beta \mathrm{Gal}^{+}$cells incorporated into CD31+ blood vessels (Figure $8 \mathrm{D}$ and Supplemental Figure 9). Importantly, antagonists of $\alpha_{4} \beta_{1}$ but not of $\beta_{2}$ integrin blocked this incorporation into the vasculature (Figure 8, D-E) and suppressed angiogenesis (Figure 8F).

Our studies indicate that integrin $\alpha_{4} \beta_{1}$, but not other integrins, potentiates progenitor/stem cell trafficking to tumors and remodeling tissues undergoing neovascularization. This integrin promotes progenitor cell attachment to the neovascular endothelium, endothelial transmigration, and new blood vessel formation in remodeling tissues. 


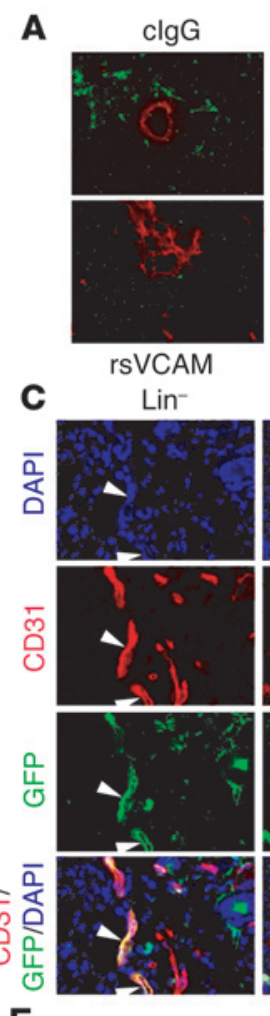

E

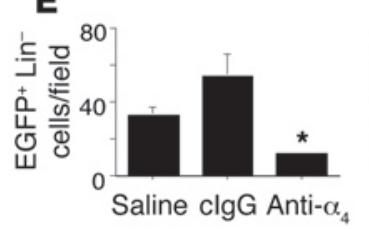

Anti- $\alpha_{4}$

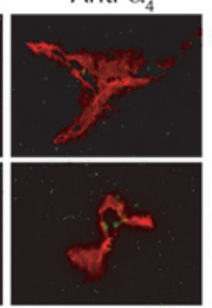

Anti-VCAM $\mathrm{Lin}^{+}$
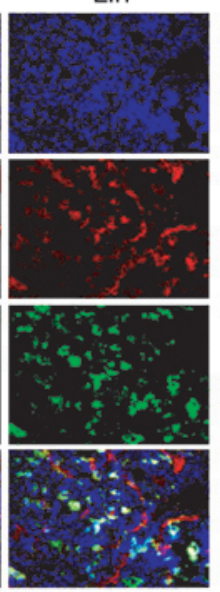

$\mathbf{F}$

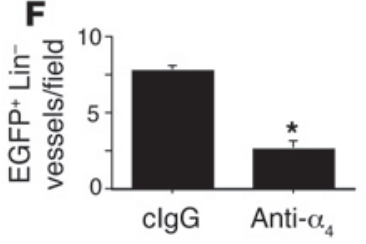

D
B
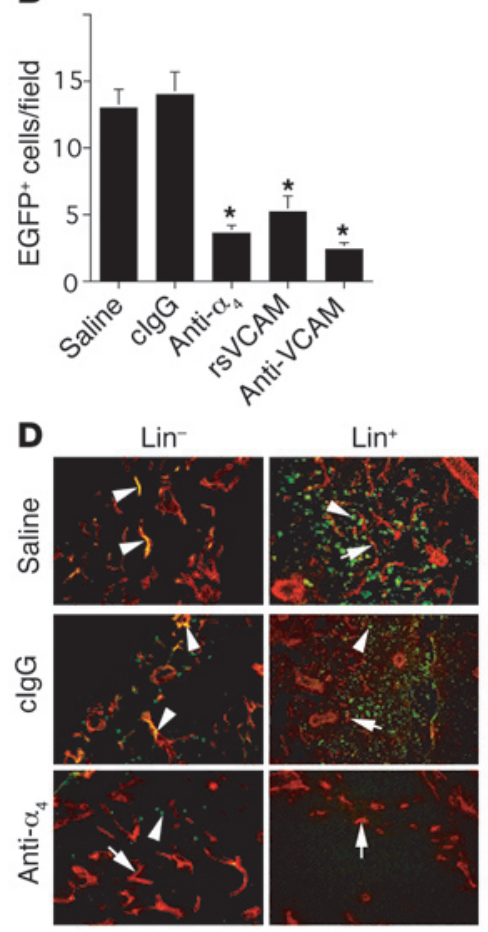

G

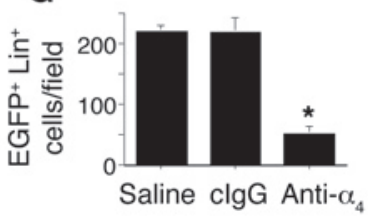

\section{Figure 6}

Integrin $\alpha_{4} \beta_{1}$ mediates homing of Lin- murine progenitor cells to tumor neovasculature. (A) High-power images of anti-CD31 (red) immunostained tumor sections from animals 12 hours after they were injected with EGFP+Lin- cells (green) in the presence of saline, isotype-matched normal rat IgG, rat anti-mouse $\alpha_{4}$, rat anti-mouse VCAM, or rsVCAM. Magnification, $\times 400$. (B) Average number of EGFP+Lin- cells per field \pm SEM from $\mathbf{A} .{ }^{*} P<0.0001$. (C) High-power images of peripheral tumor sections from animals 5 days after they were injected with either EGFP+ Lin $^{-}$ or $\mathrm{Lin}^{+}$cells that were immunostained with DAPI (blue) and anti-CD31 (red). Merged images show Lin-EGFP+ vessels in yellow. Arrowheads indicate EGFP+ cells. Magnification, $\times 400$. (D) Cryosections of LLC tumors from mice injected with EGFP+Lin- or EGFP+Lin' cells (arrowheads) and treated for 5 days with saline, isotype-matched, control anti-integrin antibodies (clgG), or anti- $\alpha_{4} \beta_{1}$ antibodies. Magnification, $\times 200$. Anti-CD31 staining (red, arrows) identifies blood vessels. EGFP+ blood vessels are yellow. (E) Average number of EGFP+Lin- cells per field \pm SEM. (F) Average number of EGFP+Lin- blood vessels \pm SEM in antibody-treated groups. (G) Average number of $\mathrm{EGFP}^{+}$cells $\pm \mathrm{SEM}$.

\section{Discussion}

Our studies demonstrate that integrin $\alpha_{4} \beta_{1}$-VCAM/fibronectin interactions promote the homing of progenitor cells and other circulating mononuclear cells to vascular endothelia during neovascularization and tissue remodeling. Our work identifies a key mechanism regulating progenitor cell homing to target tissues. This is a significant advance in our understanding of how progenitor and/or stem cells find their way to a specific tissue microenvironment. Once localized in a tissue, progenitor cells may promote tissue repair by differentiating into a number of cell types, including endothelial cells, smooth muscle cells, muscle cells, and neuronal cells (1-13). The use of $\mathrm{CD} 34^{+}$bone marrow-derived progenitor cells is thus under consideration for the therapy of diseased or damaged tissues. Development of methods to enhance homing of progenitors to target tissues could facilitate tissue repair. Our studies suggest that manipulation of the expression and/or function of $\alpha_{4} \beta_{1}$ and its ligands may improve therapeutic bone marrow transplantation or be used to inhibit progenitor/stem cell contributions to pathological processes such as tumor angiogenesis.

Integrin $\alpha_{4} \beta_{1}$-VCAM interactions promote several key heterotypic cell adhesion events in vivo. During normal embryonic development, this integrin promotes fusion of the chorion with the allantois and fusion of endocardium with myocardium (30,31). Integrin $\alpha_{4} \beta_{1}$ and fibronectin or VCAM interactions are also critical for $\mathrm{T}$ cell and natural killer cell trafficking during inflammation $(22,23)$ and cancer (32), for adhesion of immune cell precursors to bone marrow endothelia, and for circulating cell homing to the bone marrow $(24,25)$. More recently, we showed that this integrin also promotes intercellular adhesion of endothelial cells and pericytes during angiogenesis, thereby promoting subsequent blood vessel formation (21). Although previous studies showed that integrin $\alpha_{4} \beta_{1}$ antibodies mobilize progenitor cell release from bone marrow and block progenitor cell return to bone marrow $(24,25)$, our studies now show that these antibodies also block, rather than promote cell homing to neovascular tissue. The studies presented here indicate yet another role for this integrin-ligand pair, the homing of progenitor cells and other circulating bone marrowderived cells to proliferating or activated endothelia.

In our studies of progenitor cell homing to tumors, we observed that cells traveled throughout all the vessels of the tumor but only attached within the tumor vessels at the periphery of the tumor. We identified biochemical differences, expression of VCAM and fibronectin, between the peripheral and central vasculature. These differences were not attributable to central tumor necrosis, as the tumors observed were small with no evidence of necrosis. Our studies include dynamic analyses of homing as the in vivo studies successively analyzed the movement of adoptively transferred cells within a time frame of minutes (intravital microscopy), hours (N202 and LLC tumors with CD34+ cells and Lin $^{-}$cells), and days (CD34+ ${ }^{+}$and $\mathrm{Lin}^{-}$cell transfer). Use of intravital microscopy in studies of $\mathrm{CD} 34^{+}$cells could not distinguish cells adhering to the vascular wall from cells just beneath the endothelium. 


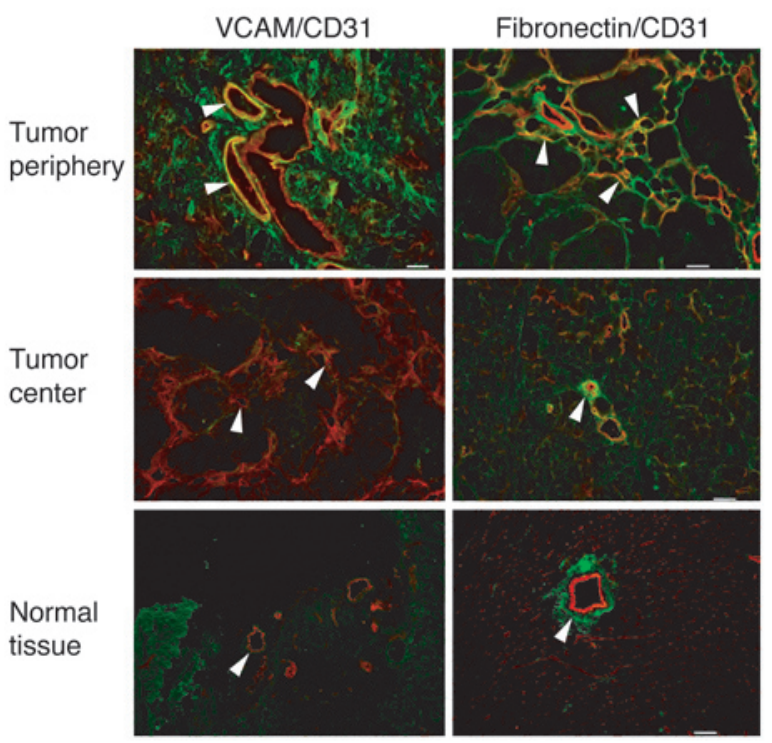

Figure 7

Integrin $\alpha_{4} \beta_{1}$ ligands are preferentially expressed at the tumor periphery. Cryosections of murine breast carcinomas or normal tissue immunostained for CD31 (red) and VCAM or fibronectin (green). Arrowheads indicate blood vessels. Yellow indicates EC expression of VCAM or fibronectin. Scale bar: $50 \mu \mathrm{m}$.

However, immunohistochemistry of thin cryosections shows that cells can be found both within vessels, adhering to the vessel wall, and inside tissues. Thus, our studies show that cells first attach to the vessel wall, then migrate into tissues. Longer term, 5-day studies show that Lin $^{-}$cells form blood vessels while others remain as single cells within the tissues. In contrast, $\mathrm{Lin}^{+}$cells never make vessels but do home to tumors and extravasate into tissues.

Our studies with human $\mathrm{CD} 34^{+}$cells and selective anti-human integrin antibodies demonstrated that human integrin $\alpha_{4} \beta_{1}$ on $\mathrm{CD}_{3} 4^{+}$cells promotes homing of progenitor cells to murine neovessels. Our studies with murine Lin $^{-}$cells and anti-murine $\alpha_{4} \beta_{1}$ antibodies reproduced these findings. The in vitro and in vivo human and murine studies combined clearly demonstrate that integrin $\alpha_{4} \beta_{1}$ on circulating progenitor cells promotes homing to neovessels. In our studies, only antagonists of integrin $\alpha_{4}$ and $\beta_{1}$ integrins blocked cell adhesion to proliferating endothelia in vitro or in vivo. Our studies utilizing antagonists of integrin $\alpha_{v} \beta_{3}, \alpha_{v} \beta_{5}, \alpha_{5} \beta_{1}$, and $\beta_{2}$ integrins demonstrated that these other integrins are unlikely to play major roles in homing of circulating cells to tumors. Recent studies have suggested that $\beta_{2}$ integrins, rather than integrin $\alpha_{4} \beta_{1}$, promote endothelial progenitor cell homing to neovessels (33). In these studies, a population of adherent PBMCs cultured in endothelial growth medium were characterized as endothelial progenitor cells and served as the basis for adoptive transfer studies. We and others have found that this population of cells are derived from monocytes, as they express myelocytic markers, including CD14, CD68, and $\alpha_{M} \beta_{2}$, and fail to express CD34 or CD133, 2 key markers of progenitor cells (34). Our studies suggest that integrin $\beta_{2}$ does not contribute to progenitor cell homing to tumors. However, as both of these integrins have been shown to promote lymphocyte trafficking, it remains possible that both receptors modulate progenitor cell trafficking in distinct clinical settings.
Our studies showed that bone marrow-derived progenitor cells home to tumor vasculature and can differentiate into endothelia, thereby participating in angiogenesis. We showed that only Linand not $\mathrm{Lin}^{+}$cells formed blood vessels. Several previous studies have shown that murine $\mathrm{Lin}^{-}$and human $\mathrm{CD} 34^{+}$bone marrowderived progenitor cell populations contain endothelial progenitor cells $(1-4,15,16,28)$. Although some controversy has arisen over the existence of bone marrow-derived endothelial precursors, recent studies have identified a common bone marrow-derived precursor for endothelial cell and hematopoietic cell lineages. For example, a common $\mathrm{Lin}^{-} \mathrm{Sca} 1^{+}$stem cell (the hemangioblast) for endothelial cell and hematopoietic cell lineages was isolated from adult murine bone marrow using single cell transplantation analysis (28), demonstrating the clear presence of common endothelia/hematopoietical progenitor cells among bone marrow-derived cell populations. Additionally, other studies have shown that endothelial and hematopoietic cells arise during embryogenesis from a common precursor cell, the hemangioblast $(35,36)$. Although recent studies demonstrated in a variety of animal models that only about $15-20 \%$ of tumor vessels arise from the bone marrow (16), other studies indicated that in the absence of sprouting angiogenesis, bone marrow-derived angiogenesis alone could promote tumor growth (15). Importantly, recently published work demonstrated that sex-mismatched human bone marrow transplant recipients who later develop cancer exhibit bone marrow-derived endothelial cells within tumor vessels (37). Furthermore, adoptively transferred CD34+ ${ }^{+}$progenitor cells promoted angiogenesis and improved heart function in animal studies (1-3). Our studies thus indicate that integrin $\alpha_{4} \beta_{1}$ mediates progenitor cell attachment to the tumor endothelium, extravasation, and, therefore, subsequent participation in blood vessel formation. As $\mathrm{Lin}^{-} \mathrm{Sca} 1^{+}$stem cells give rise to endothelial and hematopoietic cell lineages (28) and adhere to endothelia in an $\alpha_{4} \beta_{1}$-dependent manner, our studies suggest that these bone marrow-derived stem cells also home to the tumor vasculature in an $\alpha_{4} \beta_{1}$-dependent manner.

We found that both VCAM and cellular fibronectin are expressed at the tumor periphery, the location to which $\mathrm{CD} 34^{+}$cells home. Fibronectin is typically localized on the abluminal side of the blood vessel while VCAM is localized on the luminal side. It is possible that the fibronectin is accessible to circulating cells, as tumor neovasculature is characteristically leaky. Tumor-derived VEGF inhibits VE-cadherin-mediated intercellular adhesion of endothelial cells and allows circulating cells, including platelets, to contact the basement membrane of VEGF-stimulated vessels (38). It is also possible that circulating cells recognize VCAM on the luminal side of endothelia and use cellular fibronectin for migration beneath endothelia. As VCAM is also expressed on the endothelia of vessels in inflamed or ischemic tissues, it is likely that integrin $\alpha_{4} \beta_{1}$ promotes the homing of circulating progenitor cells and other bone marrow-derived mononuclear circulating cells not only to tumor tissues but also to inflamed and ischemic tissues.

Antagonists of the bone marrow-derived component of angiogenesis could be useful in combination with inhibitors of sprouting angiogenesis to most thoroughly suppress tumor angiogenesis. Additionally, our studies suggest that manipulation of the expression and function of $\alpha_{4} \beta_{1}$ and its ligands may improve therapeutic bone marrow transplantation or be used to inhibit progenitor/stem cell contributions to pathological processes such as tumor angiogenesis. 
A

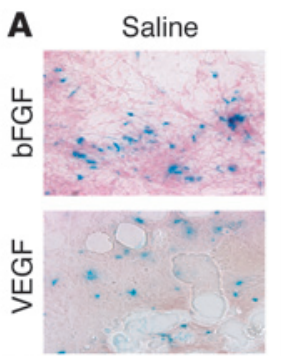

B
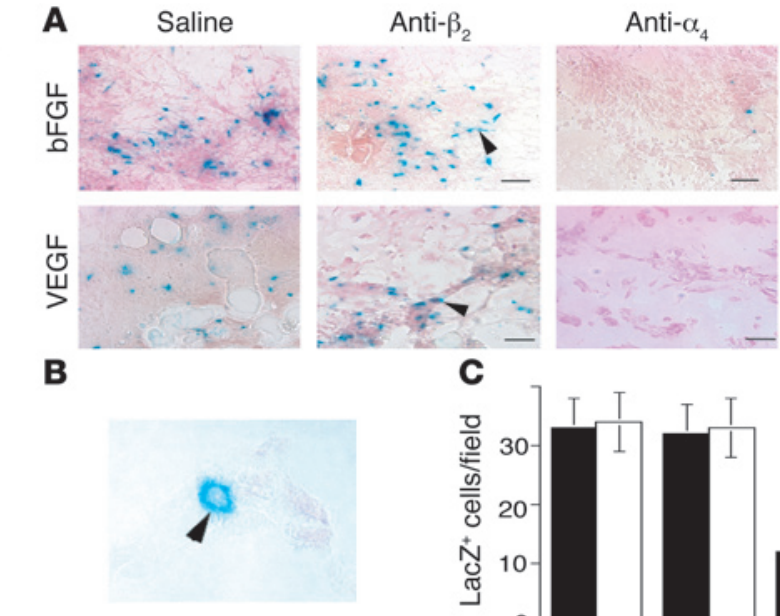

C
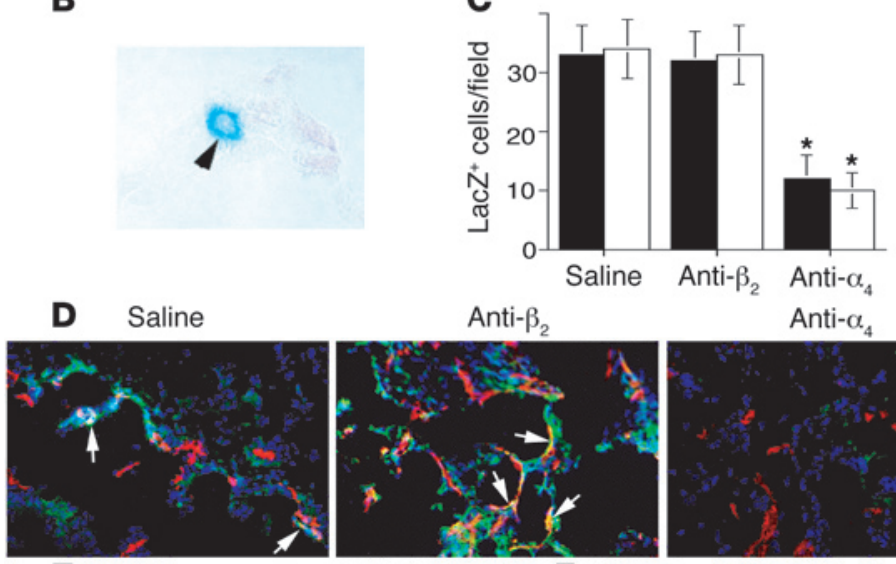

E

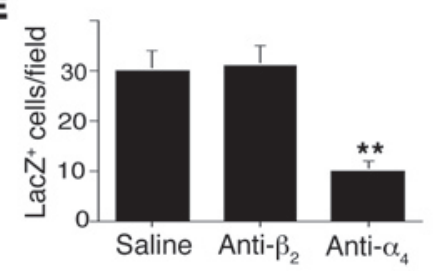
Anti- $\alpha_{4}$

$\mathbf{F}$
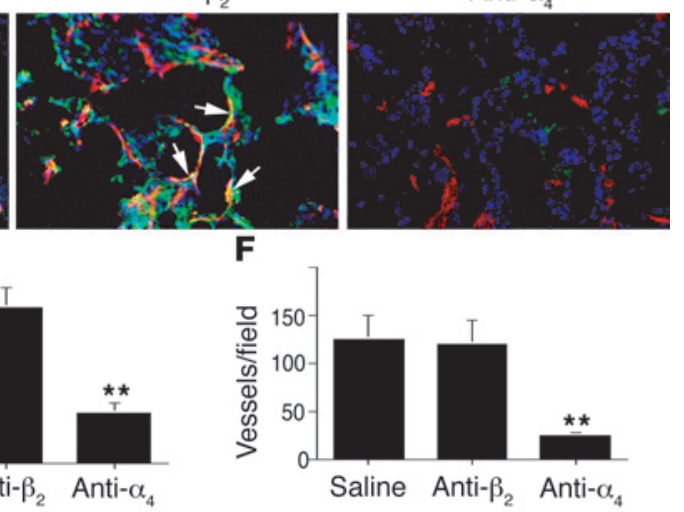

\section{Figure 8}

Integrin $\alpha_{4} \beta_{1}$ promotes stem cell homing from the bone marrow. (A) Cryosections of bFGF- or VEGF-saturated Matrigel from mice transplanted with Tie2LacZ bone marrow and treated with saline, anti- $\alpha_{4} \beta_{1}$, or control isotype-matched anti-integrin $\beta_{2}$ antibodies (clgG) were stained to detect $\beta$-galactosidase (arrowheads). Magnification, $\times 200$. Scale bars: $50 \mu \mathrm{m}$. (B) Micrograph of a $\beta$-galactosidase-positive single-celled vessel (arrowhead). Magnification, $\times 600$. (C) Average numbers of LacZ $^{+}$cells per $\times 200$ field \pm SEM in VEGF (black bars) and FGF (white bars) saturated Matrigel plugs. ${ }^{*} P<0.035$. (D) Cryosections immunostained for $\beta$-galactosidase (green) and CD31 (red). LacZ+/CD31+ vessels are yellow (arrows). (E) Average number of $\mathrm{LacZ}{ }^{+} / \mathrm{CD} 31^{+}$cells per $\times 200$ field \pm SEM. ${ }^{*} P<0.03$. (F) Average number of vessels per $\times 200$ field \pm SEM.

\section{Methods}

\section{Progenitor cell isolation}

PBMCs $\left(3.7 \times 10^{9}\right)$ were purified by gradient centrifugation from human blood obtained from the San Diego Blood Bank. From these, $3 \times 10^{6} \mathrm{CD} 34^{+}$ cells at $98 \%$ purity (as determined by FACS analysis for CD34 expression) were isolated by positive selection by 3 rounds of immune selection for human CD34 (Miltenyi Biotech).

All animal studies were approved by the Institutional Animal Care and Use Committees of UCSD, The Scripps Research Institute, and Sidney Kimmel Cancer Center. EGFP ${ }^{+}$bone marrow-derived mononuclear cells $\left(3 \times 10^{8}\right)$ were purified by gradient centrifugation from the femurs and tibias of 6 ACTB-EGFP mice. Lin ${ }^{-}$cells $\left(4.8 \times 10^{6}\right)$ were isolated from bone marrowderived mononuclear cells by 2 rounds of negative selection for a panel of lineage markers (CD5, B220, CD11b, Gr-1, 7-4, and Ter119; Miltenyi
Biotech). The selected population was $90 \%$ negative for lineage markers and $80 \%$ positive for c-kit expression. $\mathrm{Lin}^{+}$cells were $100 \%$ positive for lineage markers. Lin-Sca $1^{+}$cells $\left(70 \%\right.$ Sca $\left.1^{+}\right)$ $\left(0.4 \times 10^{6}\right)$ were isolated from Lin $^{-}$cells by 3 rounds of immune selection for the stem cell marker Sca ${ }^{+}$(Miltenyi Biotech).

\section{Intravital microscopy}

Human cells were labeled with CMTMR (Invitrogen Corp.) for 15 minutes on ice and washed. PBMCs $\left(2 \times 10^{6}\right)$ or CD $34^{+}$ cells $\left(1 \times 10^{6}\right)$ were injected i.v. in a volume of $100 \mu$ into mice with N202 syngeneic GFP ${ }^{+}$or negative tumors. N202 syngeneic breast tumor cells were cultured as tumor spheroids and were transplanted onto transplanted mammary fat-pad under transparent dorsal skinfold chambers. Animals were sedated while in vivo fluorescence microscopy was performed. Experiments were performed twice with 2 mice per treatment group. In some studies, cells were injected together with anti-integrin antibodies (final concentration of $50 \mu \mathrm{g} / \mathrm{ml} \mathrm{HP} 2 / 1$ antihuman $\alpha_{4} \beta_{1}$, P1F6 anti- $\alpha_{v} \beta_{5}$, or LM609, anti- $\alpha_{v} \beta_{3}$, or saline). Fluorescence microscopy was performed using a Mikron Instrument Microscope (Mikron) equipped with epi-illuminator and video-triggered stroboscopic illumination from a xenon arc (MV-7600; EG\&G). A silicon intensified target camera (SIT68; Dage-MTI) was attached to the microscope. A Hamamatsu image processor (Argus 20) with firmware version 2.50 (Hamamatsu Photonic System) was used for image enhancement and to capture images to a computer. Zeiss Achroplan 20×/0.5 W, Zeiss long-distance 10/0.22, and Leitz PL1/0.04 objectives were used to capture images.

FACS analysis. FACS analysis was performed at the UCSD Cancer Center Shared Resource. PE-conjugated mouse antihuman $\alpha_{4} \beta_{1}$ (9F10) and PE- $\alpha_{5} \beta_{1}$ (IIA1) were from BD. PE-conjugated anti- $\beta_{2}$ (CLB-LFA 1/1) was from eBioscience, and FITCconjugated anti-CD34 (AC136) and PE-conjugated anti-CD133 (AC133/1) were from Miltenyi Biotec. Mouse anti-human $\alpha_{v} \beta_{3}$ (FITC-conjugated LM609) and $\alpha_{v} \beta_{5}$ (PE-conjugated P1F6) were from Chemicon International. PE-conjugated rat anti-mouse $\alpha_{5} \beta_{1}$ (5H10-27), $\alpha_{\mathrm{v}}$ (RMV-7), and $\beta_{2}$ (M18/2) were from BD. PE-conjugated anti-mouse $\alpha_{4} \beta_{1}$ (R1-2), c-kit (2B8), and Sca-1 (E13-161.7) were from eBioscience, and lineage markers were from Miltenyi Biotec. Expression of VCAM on ECs was determined with P8B1 (Chemicon International). Expression of $\beta_{1}$ integrin was determined with mouse anti-human $\beta_{1}$ P4C10 (a gift of David Cheresh, Moores UCSD Cancer Center), and expression of $\beta_{7}$ integrin was determined with rat anti-human $\beta_{7}$ FIB504 (BD Biosciences - Pharmingen) followed by incubation in Alexa 488-conjugated secondary antibodies (Invitrogen Corp.). Each FACS analysis was performed 2-3 times with identical results.

Immunohistochemistry. Five micron cryosections were fixed in acetone and incubated in 5\% BSA in PBS, then in primary antibody $(5-10 \mu \mathrm{g} / \mathrm{ml})$ for 2 hours at room temperature. Slides were well washed, incubated in Alexa 488 (green), Alexa 568 (red), or Alexa 350 (blue) conjugated secondary antibody for 1 hour at room temperature, washed and, in some cases, stained with DAPI. Primary antibodies were as follows: anti-fibronectin (TV-1; Chemicon International), rat anti-mouse VCAM (M/K-2 from Chemicon International), anti-pan species VCAM (H-276, sc-8304 from Santa Cruz Biotechnology Inc.), rat anti-mouse CD31 (MEC 13.3 from BD Biosciences - Pharmingen), and mouse anti-human Ki67 (Chemicon International). Each experiment was performed 3 times. In all immunohistochemistry studies, 8-10 fields per tissue sample and 3-6 tissues were quantified. 
Adhesion assays. Adhesion assays were performed for 30 minutes on 48-well plates coated with $5 \mu \mathrm{g} / \mathrm{ml}$ of recombinant H120 CS-1 fibronectin (from Martin J. Humphries, University of Birmingham, Birmingham, United Kingdom), plasma fibronectin, or vitronectin as described (39). Assays were performed in the presence of adhesion medium or $25 \mu \mathrm{g} / \mathrm{ml}$ functionblocking anti- $\alpha_{4} \beta_{1}$ (HP2/1; a gift from Biogen), anti- $\alpha_{5} \beta_{1}$ (JBS5; Chemicon International), anti- $\alpha_{v} \beta_{5}$ (P1F6; from David Cheresh) or anti- $\alpha_{v} \beta_{3}$ (LM609; from David Cheresh), or rsVCAM (R\&D Systems). Each experiment was performed 3 times with identical results, with 4 replicates per treatment group. Statistical analysis was performed by 1 -tailed Student's $t$ test.

Additionally, 25,000 CMTMR-labeled human cells per well were plated on HUVEC monolayers in 96-well culture plates for 30 minutes at $37^{\circ} \mathrm{C}$ in the presence of $25 \mu \mathrm{g} / \mathrm{ml}(2.5 \mu \mathrm{g} / 25,000$ cells) HP2/1, JBS5, LM609, P1F6, P4C10, function-blocking anti- $\beta_{2}$ antibodies (BD Biosciences - Pharmingen), and human rsVCAM (R\&D Systems). A total of 25,000 $\mathrm{EGFP}^{+}$bone marrow mononuclear cells, $\mathrm{Lin}^{+}, \mathrm{Lin}^{-}$, and $\mathrm{Lin}^{-} \mathrm{Sca} 1^{+}$cells/well were similarly incubated on HUVEC monolayers in the presence of $25 \mu \mathrm{g} / \mathrm{ml}$ $\left(2.5 \mu \mathrm{g} / 25,000\right.$ cells) anti- $\alpha_{4} \beta_{1}$ (PS/2; a gift from Biogen), anti- $\alpha_{5} \beta_{1}(5 \mathrm{H} 10-27$; BD Biosciences - Pharmingen), anti- $\alpha_{\mathrm{v}}$ (RMV-7; BD Biosciences Pharmingen), or anti- $\beta_{2}$ (M18/2; BD Biosciences - Pharmingen). All assays were performed in HEPES-buffered HBSS containing 3\% BSA, $1 \mathrm{mM}$ $\mathrm{CaCl}_{2}, 1 \mathrm{~mm} \mathrm{MgCl}_{2}$, and $0.1 \mathrm{~mm} \mathrm{MnCl}_{2}$. Each experiment was performed 2-3 times with identical results, with 4 replicates per treatment group. Representative fields were photographed at $\times 200$, and the number of cells adhering per field was quantified in 5 fields per treatment condition. Statistical analysis was performed by Student's $t$ test.

Tumor studies. CMTMR-labeled PBMCs $\left(2 \times 10^{6}\right)$ or CD $34^{+}$cells $\left(1 \times 10^{6}\right)$ were incubated in medium, $50 \mu \mathrm{g} / \mathrm{ml}$ of low-endotoxin anti- $\alpha_{v} \beta_{3}$ (LM609), or anti-human $\alpha_{4} \beta_{1}$ (either HP2/1; Biogen or 9F10; BD) on ice for 30 minutes before injecting into nude mice bearing N202 breast carcinomas. In additional studies, $0.5 \times 10^{6} \mathrm{CD} 34^{+}$progenitor cells were similarly incubated before injecting into nude mice bearing $0.5 \mathrm{~cm}$ LLC tumors $(n=6)$. After 1 hour, animals were sacrificed. In some studies, $0.5 \times 10^{6}$ $\mathrm{GFP}^{+}$Chinese hamster ovary cells stably transfected to express integrin $\alpha_{4} \beta_{1}$ were injected i.v. into nude mice bearing 0.5 -cm LLC tumors $(n=3)$. Alternatively, $1 \times 10^{6} \mathrm{EGFP}^{+} \mathrm{Lin}^{-}$or $\mathrm{EGFP}^{+} \mathrm{Lin}^{+}$cells were injected into nude mice bearing 0.5 -cm LLC tumors. In 1 study, animals $(n=4)$ were treated upon injection of $\mathrm{EGFP}^{+} \mathrm{Lin}^{-}$cells for 12 hours with $100 \mu \mathrm{l}$ saline, $200 \mu \mathrm{g}$ low-endotoxin IgG2b (BD Biosciences - Pharmingen), $200 \mu \mathrm{g}$ lowendotoxin anti- $\alpha_{4} \beta_{1}$ (PS/2; Biogen), low-endotoxin anti-VCAM (MK-1), or $200 \mu \mathrm{g} \mathrm{rsVCAM}$. In other studies, animals $(n=6)$ were treated for 5 days with
$100 \mu \mathrm{l}$ saline, $200 \mu \mathrm{g}$ low-endotoxin anti- $\alpha_{\mathrm{M}} \beta_{2}$ (BD Biosciences - Pharmingen), or $200 \mu \mathrm{g}$ low-endotoxin anti- $\alpha_{4} \beta_{1}$ (PS/2; Biogen) every other day. Nude mice bearing $0.5-\mathrm{cm}$ HT29 colon carcinoma tumors were injected with $1 \times 10^{6} \mathrm{CMTMR}$-labeled CD34+ cells and treated for 5 days with $100 \mu \mathrm{l}$ saline, $200 \mu \mathrm{g}$ anti-human $\alpha_{4} \beta_{1}$ (HP2/1), or $200 \mu \mathrm{g}$ anti-human $\alpha_{v} \beta_{5}$ (P1F6) $(n=10)$. Prior to sacrifice, animals were injected i.v. with FITCBandiera simplicifolia lectin. Tumors plus surrounding connective tissue were excised and cryopreserved. Microvascular density was determined by counting $\mathrm{CMTMR}^{+} \mathrm{CD} 31^{+}$vessels per $\times 200$ microscopic field in 10 randomly selected fields per tumor in $10-\mu \mathrm{m}$ thick cryosections. The mean vessel density in all tumors per treatment group was determined. Studies were performed twice with identical results. Statistical significance was determined using Student's $t$ test.

\section{Bone marrow transplantation}

Bone marrow from FVB/NJ mice was transplanted into irradiated $\mathrm{FVB} / \mathrm{N}$ mice as previously described (1). After 12 weeks, mice were injected with $400 \mu \mathrm{l}$ growth factor-reduced Matrigel supplemented with $400 \mathrm{ng} / \mathrm{ml}$ of bFGF or VEGF and treated on days 1 and 3 by i.v. injection of saline, $200 \mu \mathrm{g} / \mathrm{mouse}$ rat anti-mouse $\alpha_{4} \beta_{1}$ (low-endotoxin PS/2), or rat-anti-mouse $\beta_{2}$ integrin (low-endotoxin M1/70; BD). Plugs were excised after 5 days $(n=8)$. Cryosections were incubated in X-gal or immunostained with rabbit anti- $\beta$-galactosidase and rat anti-murine CD31 (MEC13.3; BD). Experiments were performed twice with identical results. Positive vessels were quantified at $\times 200$ in 10 randomly selected microscopic fields per plug. Statistical analysis was performed by 1 -tailed Student's $t$ test.

\section{Acknowledgments}

This work was supported by grants to J. Varner from the NIH, the UCSD Cancer Center, the Charlotte Geyer Foundation, and the American Heart Association. We would like to thank Margaret Hogan for assisting with confocal microscopy and Jeanine Kleeman, Yuhong Zhu, and Robbie Cheresh for excellent technical assistance.

Received for publication February 14, 2005, and accepted in revised form January 3, 2006.

Address correspondence to: Judy Varner, Moores UCSD Cancer Center, University of California, San Diego, 3855 Health Sciences Drive, La Jolla, California 92093-0819, USA. Phone: (858) 822-0086; Fax (858) 822-1325; E-mail: jvarner@ucsd.edu.
1. Asahara, T., et al. 1997. Isolation of putative progenitor endothelial cells for angiogenesis. Science. 275:964-967.

2. Kawamoto, A., et al. 2001. Therapeutic potential of ex vivo expanded endothelial progenitor cells for myocardial ischemia. Circulation. 103:634-637.

3. Ott, I., et al. 2005. Endothelial-like cells expanded from CD34+ blood cells improve left ventricular function after experimental myocardial infarction. FASEB J. 19:992-994.

4. Otani, A., et al. 2002. Bone marrow-derived stem cells target retinal astrocytes and can promote or inhibit retinal angiogenesis. Nat. Med. 8:1004-1010.

5. Hattori, K., et al. 2001. Vascular endothelial growth factor and angiopoietin-1 stimulate postnatal hematopoiesis by recruitment of vasculogenic and hematopoietic stem cells. J. Exp. Med. 193:1005-1014.

6. Rafii, S., and Lyden, D. 2003. Therapeutic stem and progenitor cell transplantation for organ vascularization and regeneration. Nat. Med. 9:702-712.

7. Taguchi, A., et al. 2004. Administration of CD34+ cells after stroke enhances neurogenesis via angio- genesis in a mouse model. J. Clin. Invest. 114:330-338. doi:10.1172/JCI200420622.

8. Religa, P., et al. 2002. Smooth-muscle progenitor cells of bone marrow origin contribute to the development of neointimal thickenings in rat aortic allografts and injured rat carotid arteries. Transplantation. 74:1310-1315.

9. Priller, J., et al. 2001. Neogenesis of cerebellar Purkinje neurons from gene-marked bone marrow cells in vivo. J. Cell Biol. 155:733-738.

10. LaBarge, M.A., and Blau, H.M. 2002. Biological progression from adult bone marrow to mononucleate muscle stem cell to multinucleate muscle fiber in response to injury. Cell. 111:589-601.

11. Torrente, Y., et al. 2004. Human circulating AC133+ stem cells restore dystrophin expression and meliorate function in dystrophic skeletal muscle. J. Clin. Invest. 114:182-195. doi:10.1172/JCI200420325.

12. Hashimoto, N., Jin, H., Liu, T., Chensue, S.W., and Phan, S.H. 2004. Bone marrow-derived progenitor cells in pulmonary fibrosis. J. Clin. Invest. 113:243-252. doi:10.1172/JCI200418847.

13. Phillips, R.J., et al. 2004. Circulating fibrocytes traffic to the lungs in response to CXCL12 and mediate fibrosis. J. Clin. Invest. 114:438-446. doi:10.1172/ JCI200420997.

14. Carmeliet, P. 2003. Angiogenesis in health and disease. Nat. Med. 9:653-660.

15. Lyden, D., et al. 2001. Impaired recruitment of bone-marrow-derived endothelial and hematopoietic precursor cells blocks tumor angiogenesis and growth. Nat. Med. 7:1194-1201.

16. Ruzinova, M.B., et al. 2003. Effect of angiogenesis inhibition by Id loss and the contribution of bonemarrow-derived endothelial cells in spontaneous murine tumors. Cancer Cell. 4:277-289.

17. Jain, R.K., and Duda, D.G. 2003. Role of bone marrowderived cells in tumor angiogenesis and treatment. Cancer Cell. 3:515-516.

18. Nygren, J.M., et al. 2004. Bone-marrow derived hematopoietic cells generate cardiomyocytes at a low frequency through cell fusion but not transdifferentiation. Nat. Med. 5:494-501.

19. Willenbring, H., et al. 2004. Myelomonocytic cells are sufficient for therapeutic cell fusion in liver. Nat. Med. 7:744-748. 
20. Jin, H., and Varner, J. 2004. Integrins: roles in cancer development and as treatment targets. BrJ. Cancer. 90:561-565.

21. Garmy-Susini, B., et al. 2005. Integrin $\alpha_{4} \beta_{1}$-VCAM-1mediated adhesion between endothelial and mural cells is required for blood vessel maturation. J. Clin. Invest. 115:1542-1551. doi:10.1172/JCI23445.

22. Guan, J.L., and Hynes, R.O. 1990. Lymphoid cells recognize an alternatively spliced segment of fibronectin via the integrin receptor alpha 4 beta 1 . Cell. 60:53-61.

23. Elices, M.J., et al. 1990. VCAM-1 on activated endothelium interacts with the leukocyte integrin VLA-4 at a site distinct from the VLA-4/fibronectin binding site. Cell. 60:577-584.

24. Simmons, P.J., et al. 1992. Vascular cell adhesion molecule- 1 expressed by bone marrow stromal cells mediates the binding of hematopoietic progenitor cells. Blood. 80:388-395.

25. Papayannopoulou, T., Priestley, G.V., Nakamoto, B., Zafiropoulos, V., and Scott, L.M. 2001. Molecular pathways in bone marrow homing: dominant role of alpha(4)beta(1) over beta(2)-integrins and selectins. Blood. 98:2403-2411.

26. Craddock, C.F., Nakamoto, B., Andrews, R.G., Priestley, G.V., and Papayannopoulou, T. 1997. Antibodies to VLA4 integrin mobilize long-term repopulating cells and augment cytokine-induced mobilization in primates and mice. Blood. 90:4779-4788.

27. Elices, M.J., et al. 1994. Expression and functional significance of alternatively spliced CS1 fibronectin in rheumatoid arthritis microvasculature. J. Clin. Invest. 93:405-416.

28. Grant, M.B., et al. 2004. Adult hematopoietic stem cells provide functional hemangioblast activity during retinal neovascularization. Nat. Med. 8:607-612.

29. Terskikh, A.V., Miyamoto, T., Chang, C., Diatchenko, L., and Weissman, I.L. 2003. Gene expression analysis of purified hematopoietic stem cells and committed precursors. Blood. 102:94-101.

30. Yang, J.T., Rayburn, H., and Hynes, R.O. 1995. Cell adhesion events mediated by alpha 4 integrins are essential in placental and cardiac development. Development. 121:549-560.

31. Kwee, L., et al. 1995. Defective development of the embryonic and extraembryonic circulatory systems in vascular cell adhesion molecule (VCAM-1) deficient mice. Development. 121:489-503.

32. Melder, R.J., et al. 1996. During angiogenesis, vascular endothelial growth factor and basic fibroblast growth factor regulate natural killer cell adhesion to tumor endothelium. Nat. Med. 2:992-997.
33. Chavakis, E., et al. 2005. Role of beta2-integrins for homing and neovascularization capacity of endothelial progenitor cells. J. Exp. Med. 201:63-72.

34. Schmeisser, A., et al. 2001. Monocytes coexpress endothelial and macrophagocytic lineage markers and form cord-like structures in Matrigel under angiogenic conditions. Cardiovasc Res. 49:671-680.

35. Patterson, L.J., Gering, M., and Patient, R. 2005. Scl is required for dorsal aorta as well as blood formation in zebrafish embryos. Blood. 105:3502-3511.

36. Wang, L., et al. 2004. Endothelial and hematopoietic cell fate of human embryonic stem cells originates from primitive endothelium with hemangioblastic properties. Immunity. 21:31-41.

37. Peters, B.A., et al. 2005. Contribution of bone marrow-derived endothelial cells to human tumor vasculature. Nat. Med. 11:261-262.

38. Weis, S., et al. 2004. Src blockade stabilizes a Flk/ cadherin complex, reducing edema and tissue injury following myocardial infarction. J. Cell Biol. 167:223-229.

39. Kim, S., Bell, K., Mousa, S.A., and Varner, J.A. 2000. Regulation of angiogenesis in vivo by ligation of integrin alpha5beta1 with the central cell-binding domain of fibronectin. Am. J. Pathol. 156:1345-1362. 